different organisations,-the Department of Child and Family Psychiatry, the School Psychological Service and a Selection of Secondary Schools-operating within often very different conceptual frameworks, could come together and focus on common problems from their different viewpoints. This helped us to identify some of the gaps in the local services which were limiting the provision of an efficient system of support for children in difficulties. Where learning problems are part of the picture, an accurate psychological diagnosis is an essential preliminary to effective remedial help; yet many of these children would never be seen because of the inordinately large work load of the educational psychologists. This bottleneck effectively prevented the size of the problem ever becoming apparent. Where the learning problems were identified, there was a serious shortfall of remedial teachers able to offer specific help. Time after time we saw these children developing serious emotional difficulties, attributable at least in part to their learning problems. We would welcome more local educational provision, in the form of a tutorial unit for example, to which children could be withdrawn for specific help, but with the clear aim of re-integrating them into their normal schools later. Alternatively, could support units within schools take over this function, with specialist teachers trained specifically to help children with emotional and learning problems, and with a clearly defined input from the specialist support systems of educational psychology, child psychiatry, social work and the school medical service?

In this way perhaps we can realise more fully our aim of providing support to the schools, so that they can help themselves to become more therapeutically effective for troubled children.

\section{ACKNOWLEDGEMENTS}

My grateful thanks are due to Robert Collman, Educational Psychologist, Pamela Roberts, Senior Social Worker and our teaching colleagues who have participated in the meetings.

REFERENCES

'Rutter, M., MAugham, B., Mortimore, P. \& OUston, J. (1979) Fifteen Thousand Hours; Secondary Schools and their Effects on Children. London: Open Books.

2__, - TIZARd, J. \& Whitmore, K. (ods) (1970) Education, Health and Behaviour. London: Longman.

${ }^{3}$ VARLAAM, A. (1974) Educational attainment and behaviour at school. Greater London Council Intelligence Quarterly, no. 29, 29-37.

\title{
Ex-phobic Volunteers in the Treatment of Agoraphobic Patients
}

\author{
PETER TYRer, Consultant Psychiatrist, Mapperley Hospital, Nottingham
}

\begin{abstract}
Although behaviour therapy, primarily in the form of gradual and prolonged exposure to phobic situations, is now well established as the treatment of choice in most cases of agoraphobia ${ }^{1,2}$ not all suitable patients receive this treatment. This is partly because behaviour therapy is time-consuming and, although there have been great gains made in recent years with the establishment of training for nurses in behaviour therapy, ${ }^{3}$ in many peripheral hospitals few nurses have the necessary training. There are increasing demands made upon the time of the community psychiatric nurse and it seems likely that the proportion spent in behaviour therapy will be squeezed to a level that will deprive some patients of its benefits.

We therefore need alternative ways of delivering this treatment to those in need. In the course of developing psychiatric clinics in general practice ${ }^{4.5}$ it was noticed that many phobic patients attended who had not been seen by the psychiatric services before. This was mainly because the clinics were nearer their homes and they felt less anxious about attending a general practice than a hospital clinic. It was also realised that there was no possibility of treating all these patients with existing nursing and psychological resources. As several patients who had been successfully treated by behaviour therapy expressed an
\end{abstract}

interest in helping others with similar problems we felt it reasonable to explore the use of this 'hidden resource' in the treatment of new phobic patients.

\section{The new behaviour therapists}

All out-patients with phobic disorders referred from the north and east of Nottingham over a two year period were considered if their primary disorder was that of agoraphobia and they agreod to be seen by a volunteer therapist. All patients maintained contact with the referring psychiatrist during treatment although this was infrequent with no direct supervision of the volunteers. In addition the therapists saw some patients with phobic symptoms for advice on coping with them but did not get formally involved with therapy unless the primary diagnosis was that of a phobic disorder.

Thirty-four patients were seen in the course of the two years and 16 received a full programme of home-based graded exposure derived from established procedures. ${ }^{6}$ Of the remaining 18,10 were seen on one occasion only for advice, five received treatment but their therapists did not complete a full set of questionnaires, two dropped out of treatment within the first month and one was seen by a therapist without any formal psychiatric involvement.

Assessments were made with the Fear Questionnaire of Marks \& Mathews. ${ }^{7}$ The questionnaires were given to each patient before treatment and after four weeks and 10 weeks. The volunteers were asked to see their clients on approximately 10 occasions during this period but the frequency of contact was left flexible. 
Of the 18 patients seen regulariy for at least two months, most had severe phobias and had either received previous treatment or had refused treatment based on hospital because of their severity of agoraphobia.

Nine therapists were involved in treatment. Eight of these had been treated for phobic symptoms in the year before becoming a volunteer therapist. Several of the patients still had considerable phobic symptomatology and a husband and wife who were too phobic to travel alone administered their treatments as a couple. One of the therapists was treated as a patient carly on in the study, recovered and then offered her services as a therapist with other patients. The therapists' ages ranged between 27 and 60 , and seven of them were women. None of them had any other involvement with self help groups for agoraphobia. Seven of the patients had previously received behaviour therapy for their phobic symptoms.

Each treatment involved an explanation of the principles of gradual exposure to phobic stimuli and a setting of targets to be completed by the patient. ${ }^{6}$ Each patient practised between assessments and new targets were set depending on what had been achieved between each visit. Close relatives of the patient were sometimes involved in the planning of targets and in helping patients to achieve them.

The patients did not discuss their targets individually with professional staff but at intervals of three to four months all the therapists met with the staff at a day hospital to discuss any problems they had encountered in their treatment and to share their experiences.

\section{Outcome}

The scores for (a) mean overall phobia (range 0-8), (b) the agoraphobic symptom total and (d) other phobic scores from the Fear Questionnaire were analysed separately by one-way analysis of variance. There was a significant reduction in the mean overal phobia over the period of treatment $(P<0.025$ [Figure]). The agoraphobic symptoms analysed separately showed improvement but did not quite achieve statistical significance using a two-tailed test $(P<0.1)$ and other phobic symptoms showed correspondingly less improvement $(P>0.1)$.
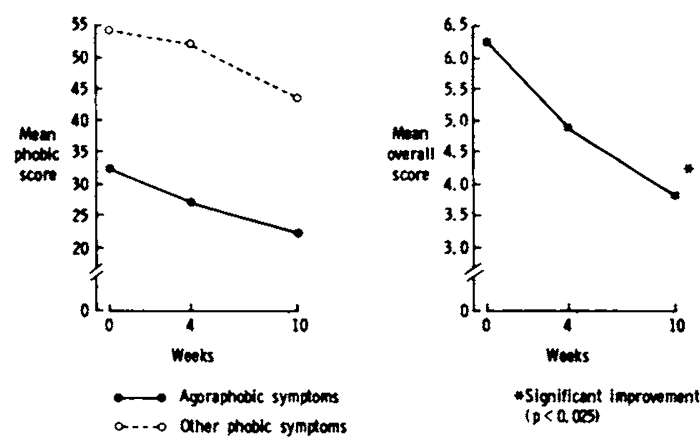

Frg. Mean overall phobic, agoraphobic and other phobic symptom scores in 16 patients before treatment and after 4-10 weeks.

Of the 18 patients who did not receive a full course of exposure therapy or did not have a full set of ratings completed mean initial scores were similar but rather less than the mean initial scores of the patients completing the full treatment course. Of the nine volunteer therapists three dropped out of the scheme before the end of the two year period. In each case they had lost all their phobic symptoms and had taken on other activities, including part-time jobs. All three told us that their volunteer work had helped to overcome their phobias and once they had been conquered completely

TABLE

Summary of patients' views of their treatment and therapists $(n=16)$

\begin{tabular}{lcccc}
\hline & $\begin{array}{c}\text { Yes, very } \\
\text { much }\end{array}$ & $\begin{array}{c}\text { Yes, a } \\
\text { little }\end{array}$ & $\begin{array}{c}\text { No, not } \\
\text { much }\end{array}$ & $\begin{array}{c}\text { No, not } \\
\text { at all }\end{array}$ \\
\cline { 2 - 5 } $\begin{array}{l}\text { Very } \\
\text { helpful }\end{array}$ & 8 & 6 & 2 & 0 \\
& No difficulty & $\begin{array}{c}\text { No, few } \\
\text { difficulties }\end{array}$ & $\begin{array}{c}\text { Yes, some } \\
\text { difficulties }\end{array}$ & $\begin{array}{c}\text { Yes, many } \\
\text { difficulties }\end{array}$ \\
\cline { 2 - 5 } $\begin{array}{l}\text { Difficulties } \\
\text { with } \\
\text { volunteer }\end{array}$ & 11 & 3 & 2 & 0 \\
& $\begin{array}{c}\text { Yes, very } \\
\text { helpful }\end{array}$ & $\begin{array}{c}\text { Yes, quite } \\
\text { helpful }\end{array}$ & $\begin{array}{c}\text { No, not very } \\
\text { helpful }\end{array}$ & $\begin{array}{c}\text { No, not } \\
\text { helpful at all }\end{array}$ \\
\cline { 2 - 6 } $\begin{array}{l}\text { Could } \\
\text { treatment } \\
\text { help others? }\end{array}$ & 7 & 6 & 3 & 0 \\
\hline
\end{tabular}

they did not feel the same motivation to help others. It therefore seemed as though the therapists themselves were gaining a considerable amount from treatment and were less altruistic than might at first appear.

The results of the questionnaire sent to the patients after the completion of treatment are summarised (Table). This showed that most patients were satisfied with their treatment and had no diffculties in working with a volunteer therapist. Patients were also asked to comment separately about their treatment if they wished. These comments varied from the congratulatory ('An excellent scheme'; 'Absolutely marvellous'; 'Mrs X is lovely') to the neutral ('The progress I made was limited but the helpful and relaxed attitude of Mrs Y would have been a great boost') and the mildly critical ('I don't think two people with phobias are any good to each other because when they arrive shaking and afraid they put you in a worse state yourself). Two patients broke off treatment with their volunteer therapists before completion. One complained because her volunteer criticised his wife for not following the volunteer's instructions about doing outside activities on behalf of her husband. The second felt embarrassed because the volunteer lived only a hundred yards away from her home and thought that the neighbours might gossip. After these experiences we confirmed with the therapists that they should not involve other people in the treatment of phobias unless this was with the full approval of the patient and we also arranged for volunteers to see patients at least a mile away from their own homes.

One patient was so pleased with the help she received from her volunteer therapist that she wrote to a national newspaper, which printed her letter and visited the therapist to present her with a large bouquet of flowers.

\section{Comment}

At the beginning of this study there was concern from several members of the hospital staff that ex-patients might not be suitable as therapists. Doubts about confidentiality and the ability of ex-patients to avoid over-involvement were expressed in particular. In fact virtually no concern 
was expressed about the confidentiality of interviews with ex-patients and there was no evidence of excessive dependence on one or more of the volunteer therapists. The results show that the therapists achieved a moderate degree of success. Only four patients failed to make any improvement and all of them had been treated before by community psychiatric nurses or psychologists. Four other patients who had failed to respond to behaviour therapy from professionals made significant improvement with the volunteer therapists. When asked about this subsequently these patients explained their better results by stating that the volunteer therapists had greater understanding of their problem because in most cases they had experienced exactly the same symptoms. This, combined with the evidence that the patient had clearly improved, seems to have had a beneficial effect on motivation and ability to complete the exposure programme.

An interesting, and unexpected, aspect of the study was the improvement made by the volunteer therapists. Although no formal ratings were made of their phobic symptoms most still had residual phobic problems when they became volunteers. The successful treatment of the patient led to a corresponding improvement in the therapist's symptoms. Once the therapist had conquered phobic symptoms entirely there tended to be less interest in continuing the volunteer work. Of the nine therapists involved in treatment none continued to act as therapists throughout the two years of the study. In some ways this is understandable, as the therapists only received travelling expenses for work that occupied many hours.

It is difficult to decide on the place of this type of management for agoraphobic patients in general. The advantage of our volunteer service was that all treatment could be home-based, with its attendant advantages, ${ }^{8}$ and much more time could be given than that available from professional staff. However, it has been shown that success in exposure therapy does not necessarily depend on personal contact with a therapist. ${ }^{9}$ There was also no control group in the study so that it is impossible to compare the efficacy of volunteer therapists compared with other forms of treatment.
Nevertheless, the study suggests that ex-patients can be good behaviour therapists and in some cases have the edge on professionals through having personal experience of the symptoms their patients are suffering. At a time when psychiatric services require an increase in community resources without much extra money being available it is reasonable to consider this hidden resouce of therapeutic endeavour. There seems no reason why it should not be extended beyond behaviour therapy for agoraphobic patients although more evidence is needed.

\section{ACKNOWLEDGEMENTS}

This study was supported by a grant from the Mental Health Foundation. I thank David Fewtrell and Joy Atkins for their help in training the volunteers, and Shirley Joomrally, Mavis Fell and George Bassett of the Plains Day Hospital, Nottingham for their support and advice to the therapists during treatment.

\section{REFERENCES}

${ }^{1}$ Hand, I., Lamontagne, Y. \& Marks, I. M. (1974) Group exposure (flooding) in vivo for agoraphobics. British Journal of Psychiatry, 124, 588-602.

${ }^{2}$ MARKS, I. (1981) Cure and Care of Neurosis: Theory and Practice of Behavioural Psychotherapy. New York: Wiley.

${ }^{3}$ BrRD, J., MArKs, I. M. \& LindLEY, P. (1979) Nurse therapist in psychiatry: some developments, controversies and implications. British Journal of Psychiatry, 135, 321-329.

'TyRER, P. (1984) Psychiatric clinics in general practice: an extension of community care. British Journal of Psychiatry, 145, 9-14.

3 - Seivewright, N. \& Wollerron, S. (1984) General practice psychiatric clinics: impact on psychiatric services. British Journal of Psychiatry, 145, 15-19.

${ }^{6}$ Matthews, A. M., Gelder, M. G. \& Johnston, D. W. (1981) Agoraphobia: Nature and Treatment. London: Tavistock.

'MARKS, I. M. \& MATHEWS, A. M. (1979) Brief standard self-rating phobic patients. Behaviour Research and Therapy, 17, 263-267.

Jjannoun, L., Munay, M., Catalan, J. \& Gelder, M. (1980) A home-based treatment program for agoraphobia: replication and controlled evaluation. Behaviour Therapy, 11, 294-305.

'Ghosh, A., Marks, I. M. \& Carr, A. C. (1984) Self exposure treatment for phobias: a controlled study. Journal of the Royal Society of Medicine, 77, 483-487.

\section{Gibbens Fellowship in Criminology}

In memory of the late Professor T. C. N. Gibbens, the Institute of Psychiatry has established a biennial Gibbens Fellowship in Criminology. The Fellowship is to be applied for the advancement of criminology and/or the improvement of clinical work with offenders. The trustees will consider applications from any relevant professional person, and for a wide range of purposes (e.g. to carry out an enquiry; to buy a piece of equipment; to travel to develop new ideas; to learn a new skill). The award is not available for attendance on a course, nor to pay course fees.

There are no application forms. Applicants are asked to write in confidence to the Trustees, c/o Professor John Gunn, Institute of Psychiatry, De Crespigny Park, Denmark Hill, London SE5 8AF, giving details of their professional background and area of interest, the subject of their proposal with an estimate of its time and cost, and an indication of how the completed project might benefit the applicant and his or her work. Short-listed applicants will be invited to discuss their proposal with the Trustees and the successful applicant(s) will be expected to write an account of the use to which the award has been put at a later date. 